\title{
Spinocerebellar ataxia type 35
}

INSERM

\section{Source}

INSERM. (1999). Orphanet: an online rare disease and orphan drug data base.

Spinocerebellar ataxia type 35. ORPHA:276193

Spinocerebellar ataxia type 35 (SCA35) is a subtype of autosomal dominant cerebellar ataxia type 1 (ADCA type 1; see this term) characterized by the adult-onset of progressive gait and limb ataxia, dysarthria, ocular dysmetria, intention tremor, hyperreflexia and spasmodic torticollis. 